\title{
EXPONENTIAL DICHOTOMIES OF A NON-CLASSICAL EQUATION IN SPACES OF DIFFERENTIAL FORMS ON A TWO-DIMENSIONAL TORUS WITH "NOISES"
}

\author{
O. G. Kitaeva, South Ural State University, Chelyabinsk, Russian Federation, \\ kitaeavaog@susu.ru,
}

We study the stability of solutions to the linear stochastic Barenblatt - Zheltov Cochina equation in spaces of smooth differential forms defined on a two-dimensional torus. We show the existence of stable and unstable invariant spaces of solutions in spaces of "noises" for various parameters characterizing the medium and properties of the fluid. Also, we prove the existence of exponential dichotomies of solutions, which consist in the splitting of the phase space into a direct sum of two invariant spaces. Moreover, solutions starting in one of these spaces increase exponentially, remaining in this space, and solutions starting in another space decrease exponentially, also remaining in this space. We construct an algorithm to find stable and unstable solutions to the stochastic Barenblatt - Zheltov Cochina equation on one of the maps of a two-dimensional torus. The algorithm takes into account that the initial data belong to the phase space. The algorithm is implemented in the Maple environment. For various values of the parameters included in the Barenblatt Zheltov - Cochina equation, we present graphs of exponentially stable and exponentially unstable solutions that belong to stable and unstable invariant spaces. Also, we present the graphs of solutions having exponential dichotomy.

Keywords: Sobolev type equation; stochastic equations; differential forms; exponential dichotomies.

\section{Introduction}

The Barenblatt - Zheltov - Cochina equation

$$
(\lambda-\Delta) u_{t}=\alpha \Delta u+f
$$

simulates the dynamics of the pressure of a fluid filtered in a fractured porous medium. The real parameters $\alpha$ and $\lambda$ characterize the medium and properties of the fluid, respectively, and the function $f=f(x)$ presents an external influence.

In [1], in order to study the initial - boundary value problems for the Barenblatt Zheltov - Cochina equation, equation (1) is reduced to the Cauchy problem

$$
u(0)=u_{0}
$$

for the linear Sobolev type equation

$$
L \dot{u}=M u+f
$$

in the suitable function spaces. The paper [2] was the first to consider dichotomies of solutions to homogeneous Sobolev type equation (1), where the operator $M$ is relatively spectrally bounded. The paper [3] proves the existence of invariant spaces of equation (1) in spaces of differential forms defined on smooth Riemannian manifolds without boundary. 
The numerical solution of equation (1) was started in [4]. The paper [5] considers equation (1) on graphs. The paper [6] is devoted to the study of the asymptotic stability of the Barenblatt - Zheltov - Cochina equation in the sense of Lyapunov. Here the Lyapunov function method is applied, and a computational experiment based on the Galerkin method is constructed.

The study of the stochastic Sobolev type equations

$$
L \stackrel{\circ}{\eta}=M \eta+N \omega
$$

where $\eta=\eta(t)$ is the desired stochastic process, $\stackrel{\circ}{\eta}$ is its Nelson - Gliklikh derivative [7], is presented, for example, in [8] - [12]. The paper [13] considers high-order stochastic Sobolev type equations, the paper [14] considers the multipoint problem for equation (4). The paper [15] proves the existence of solutions to equation (4) in the space of differential forms. The paper [16] considers the question on the existence of exponential dichotomies of these solutions.

The aim of this work is to construct an algorithm to find stable and unstable solutions to stochastic equation (4) in the space of differential forms on a two-dimensional torus. In addition to Introduction and References, the article consists of two sections. In Section 1, we construct spaces of random $\mathbf{K}$-variables and $\mathbf{K}$-"noises" on a two-dimensional torus, and consider the stable and unstable invariant spaces of the stochastic Barenblatt - Zheltov Cochina equation in space of differential forms. In Section 2, we construct a numerical algorithm, and present the graphs of solutions in cases where solutions are exponentially stable, exponentially unstable, and in cases where there exist exponential dichotomies.

\section{Exponential Dichotomies of the Stochastic Barenblatt - Zheltov - Cochina Equation in Spaces of Differential Forms}

On the two-dimensional torus $T^{2}=[0,1] \times[0,1]$, consider the following space of differential forms $E^{q}=E^{q}\left(T^{2}\right), q=0,1,2$ :

$$
a=\sum_{i_{1}<i_{2}} a_{i_{1}, i_{2}} d x_{i_{1}} \wedge d x_{i_{2}}
$$

where $a_{i_{1}, i_{2}} \in C^{\infty}, q=0,1,2$. In particular, the space of 0 -forms $E^{0}\left(\mathbb{R}^{2}\right)$ is the space of functions of two variables. Define the Laplace - Beltrami operator $\Delta: E^{q} \rightarrow E^{q}$ by the equality $\Delta=\delta d+d \delta$, where $d: E^{q} \rightarrow E^{q+1}$ is the operator of external differentiation, $\delta: E^{q} \rightarrow E^{q-1}, \delta=(-1)^{2 q+3} * d *, *: E^{q} \rightarrow E^{2-q}$ is the Hodge operator. Taking into account the splitting (see [17])

$$
E^{q}=\Delta\left(E^{q}\right) \oplus H^{q \perp}=d \delta\left(E^{q}\right) \oplus \delta d\left(E^{q}\right) \oplus H^{q \perp},
$$

we obtain that the equation $\Delta \omega=\alpha$ has a solution $\omega \in E^{q}$ exactly when the $q$-form $\alpha$ is orthogonal to the space of harmonic forms $H^{q \perp}=\left\{\omega \in E^{q}: \Delta \omega=0\right\}$.

In spaces $E^{q}, q=0,1,2$, define the scalar product by the formulas

$$
<a, b>_{0}=\int_{T^{2}} a \wedge * b,
$$




$$
\begin{aligned}
& <a, b>_{1}=<a, b>_{0}+<\Delta a, b>_{0}, \\
& <a, b>_{2}=<a, b>_{1}+<\Delta a, \Delta b>_{0},
\end{aligned}
$$

and denote the corresponding norm by $\|\cdot\|_{l}$. Denote by $H_{l}^{q}$ the completions of the lineal $E^{q}$ with respect to the norm $\|\cdot\|_{l}, l=0,1,2$. Note that we have continuous and dense embeddings $H_{2}^{q} \subset H_{1}^{q} \subset H_{0}^{q}$.

On the two-dimensional torus $T^{2}$, define the spaces of $\mathbf{K}$-variables and $\mathbf{K}$-"noises". Let $\Omega \equiv(\Omega, \mathcal{A}, \mathbf{P})$ be a complete probability space, $\mathbb{R}$ be set of real numbers endowed with a Borel $\sigma$-algebra. A measurable mapping $\xi: \Omega \rightarrow \mathbb{R}$ is called a random variable. A set of random variables with zero mathematical expectation and finite dispersion forms the Hilbert space $\mathbf{L}_{\mathbf{2}}$ with the scalar product $\left(\xi_{1}, \xi_{2}\right)=\mathbf{E} \xi_{1} \xi_{2}$. Let $\mathcal{A}_{0}$ be a $\sigma$-subalgebra of the $\sigma$-algebra $\mathcal{A}$. Construct the subspace $\mathbf{L}_{2}^{0} \subset \mathbf{L}_{2}$ of random variables measurable with respect to the $\sigma$-subalgebra $\mathcal{A}_{0}$ of the $\sigma$-algebra $\mathcal{A}$. A conditional expectation $\mathbf{E}\left(\xi \mid \mathcal{A}_{0}\right)$ of the random variable $\xi$ is called $\Pi \xi$, where $\Pi: \mathbf{L}_{\mathbf{2}} \rightarrow \mathbf{L}_{\mathbf{2}}^{0}$ is an orthoprojector. A measurable mapping $\eta: \mathbb{R} \times \Omega \rightarrow \mathbb{R}$ is called a stochastic process, and a function $\eta(t, \cdot), t \in \mathfrak{I}$, is called a trajectory of the stochastic process. The stochastic process $\eta$ is called continuous, if a.s. (almost sure) all its trajectories are continuous (i.e., the trajectories $\eta(\cdot, \omega)$ are continuous for a.a. (almost all) $\omega \in \Omega$ ). A set of continuous stochastic processes forms a Banach space, which we denote by the symbol $\mathbf{C L}_{2}$.

Fix $\eta \in \mathbf{C L}_{2}$ and $t \in \mathfrak{I}$, denote $\mathbf{E}_{t}^{\eta}=\mathbf{E}\left(\cdot \mid \mathcal{N}_{t}^{\eta}\right)$, where $\mathcal{N}_{t}^{\eta}$ is a $\sigma$-algebra generated by the random variable $\eta(t)$.

Definition 1. Let $\eta \in \mathbf{C L}_{\mathbf{2}}$. By a Nelson-Gliklikh derivative $\stackrel{\circ}{\eta}$ of the stochastic process $\eta$ at the point $t \in \mathfrak{I}$ we mean a random variable

$$
\stackrel{\circ}{\eta}=\frac{1}{2}\left(\lim _{\Delta t \rightarrow 0+} \boldsymbol{E}_{t}^{\eta}\left(\frac{\eta(t+\Delta t, \cdot)-\eta(t, \cdot)}{\Delta t}\right)+\lim _{\Delta t \rightarrow 0+} \boldsymbol{E}_{t}^{\eta}\left(\frac{\eta(t, \cdot)-\eta(t-\Delta t, \cdot)}{\Delta t}\right)\right)
$$

if the limit exists in the sense of a uniform metric on $\mathbb{R}$.

Denote by $\mathbf{C}^{l} \mathbf{L}_{2}, l \in \mathbb{N}$ the space of stochastic processes whose trajectories are a.s. differentiable by Nelson - Gliklikh on $\mathfrak{I}$ up to the order $l$ inclusive. The spaces $\mathbf{C}^{l} \mathbf{L}_{2}$ are called the spaces of differentiable "noises".

Next, we construct the space of random $\mathbf{K}$-variables in $H_{l}^{q}$, where the basis $\left\{\varphi_{k}\right\}$ is formed by the eigenfunctions of the Laplace - Beltrami operator, which are orthonormalized by $\langle\cdot, \cdot\rangle_{l}, l=0,1,2$. Let $\mathbf{K}=\left\{\lambda_{k}\right\}$ be a monotone sequence such that $\sum_{k=1}^{\infty} \lambda_{k}^{2}<+\infty$. Denote by $\mathbf{H}_{l \mathbf{K}}^{q} \mathbf{L}_{2}, l=0,1,2$, the Hilbert space, which is the completion of the linear span of random $\mathbf{K}$-variables

$$
\eta=\sum_{k=1}^{\infty} \lambda_{k} \xi_{k} \varphi_{k}
$$

with respect to the norm

$$
\|\eta\|_{\mathbf{H}_{l \mathbf{K}}^{q} \mathbf{L}_{2}}=\sum_{k=1}^{\infty} \lambda_{k}^{2} \mathbf{D} \xi_{k},
$$

where the sequence of random variables $\left\{\xi_{k}\right\} \subset \mathbf{L}_{2}, \mathbf{D} \xi_{k} \leq$ const, $k \in \mathbb{N}$. 
Let the interval $\mathfrak{I}=(\varepsilon, \tau) \subset \mathbb{R}$. The map $\eta:(\varepsilon, \tau) \rightarrow \mathbf{H}_{l \mathbf{K}}^{q} \mathbf{L}_{2}$ defined by the formula

$$
\eta(t)=\sum_{k=1}^{\infty} \lambda_{k} \xi_{k}(t) \varphi_{k}
$$

where a sequence $\left\{\xi_{k}\right\} \subset \mathbf{C L}_{2}$, is called a continuous stochastic $\mathbf{K}$-process, if the series on the right-hand side converges uniformly on any compact set in $\mathfrak{I}$ with respect to the norm $\|\cdot\|_{\mathbf{C L}_{2}}$, and the trajectories of the process $\eta=\eta(t)$ are a.s. continuous. A continuous stochastic $\mathbf{K}$-process $\eta=\eta(t)$ is called a continuously differentiable by Nelson - Gliklikh on $\mathfrak{I}$, if the series

$$
\stackrel{\circ}{\eta}(t)=\sum_{k=1}^{\infty} \lambda_{k} \stackrel{\circ}{\xi}_{k}(t) \varphi_{k}
$$

converges uniformly on any compact set in $\mathfrak{I}$ with respect to the norm $\|\cdot\|_{\mathbf{C L}_{2}}$, and the trajectories of the process $\stackrel{\circ}{\eta}=\stackrel{\circ}{\eta}(t)$ are a.s. continuous. Let $\mathbf{C}\left(\mathfrak{I}, \mathbf{H}_{l \mathbf{K}}^{q} \mathbf{L}_{2}\right)$ be the space of continuous stochastic $\mathbf{K}$-processes, and $\mathbf{C}^{l}\left(\mathbf{H}_{l \mathbf{K}}^{q} \mathbf{L}_{2}\right)$ be the space of stochastic $\mathbf{K}$-processes that are continuously differentiable up to the order $l \in \mathbb{N}$.

Consider the question on the stability of equation (1) in the spaces $\mathbf{H}_{0 \mathbf{K}}^{q} \mathbf{L}_{2}$. Denote

$$
L=(\lambda+\Delta), M=\alpha \Delta,
$$

where $\Delta$ is the Laplace - Beltrami operator. Consider the stochastic equation with differential forms

$$
L \stackrel{\circ}{\eta}=M \eta
$$

with the Cauchy condition

$$
\eta(0)=\eta_{0}
$$

Definition 2. The set $\mathfrak{P} \subset \mathbf{H}_{0 \mathbf{K}}^{q} \mathbf{L}_{2}$ is called a phase space of equation (11), if

(i) a.s. each trajectory of the solution $\zeta=\zeta(t)$ to equation (11) belongs to $\mathfrak{P}$, i.e. $\zeta(t) \in \mathfrak{P}, t \in \mathbb{R}_{+}$, for a.a. trajectories;

(ii) there exists a unique solution to problem (11), (12) for a.a. $\zeta_{0} \in \mathfrak{P}$.

Theorem 1. [15] For any $\alpha \in \mathbb{R} \backslash\{0\}, \lambda \in \mathbb{R} \backslash\{0\}, \eta_{0} \in \mathbf{H}_{0 \mathbf{K}}^{q} \mathbf{L}_{2}$, there exists the unique solution $\eta=\eta(t)$ to problem (11), (12), and the solution has the form

$$
\eta(t)=\sum_{l=1}^{\infty},\left[\exp \left(\frac{\alpha \nu_{l}}{\lambda-\nu_{l}} t\right)\left(\sum_{k=1}^{\infty} \lambda_{k} \xi_{k}\left(\varphi_{k}, \varphi_{l}\right)_{2} \varphi_{l}\right)\right]
$$

Definition 3. The subspace $\mathbf{I}_{\mathbf{K}} \mathbf{L}_{2} \subset \mathbf{H}_{0 \mathbf{K}}^{q} \mathbf{L}_{2}$ is called an invariant space of equation (11), if the solution to problem (11), (12) $\eta \in \mathbf{C}^{1}\left(\mathbb{R} ; \mathbf{I}_{\mathbf{K}} \mathbf{L}_{2}\right)$ for any $\eta_{0} \in \mathbf{I}_{\mathbf{K}} \mathbf{L}_{2}$.

Definition 4. The solutions $\eta=\eta(t)$ to equation (11) have exponential dichotomy, if

(i) the phase space $\mathfrak{P}$ of equation (11) splits into the direct sum of two invariant spaces (i.e. $\mathfrak{P}=\mathbf{I}_{\mathbf{K}}^{+} \mathbf{L}_{2} \oplus \mathbf{I}_{\mathbf{K}}^{-} \mathbf{L}_{2}$ ), and

(ii) there exist the constants $N_{k} \in \mathbb{R}_{+}, \nu_{k} \in \mathbb{R}_{+}, k=1,2$, such that

$$
\begin{array}{ll}
\left\|\eta^{1}(t)\right\|_{\mathbf{U}} \leq N_{1} e^{-\nu_{1}(s-t)}\left\|\eta^{1}(s)\right\|_{\mathbf{U}} & \text { for } \quad s \geq t \\
\left\|\eta^{2}(t)\right\|_{\mathbf{U}} \leq N_{2} e^{-\nu_{2}(t-s)}\left\|\eta^{2}(s)\right\|_{\mathbf{U}} & \text { for } \quad t \geq s,
\end{array}
$$


where $\eta^{1}=\eta^{1}(t) \in \mathbf{I}_{\mathbf{K}}^{+} \mathbf{L}_{2}$ and $\eta^{2}=\eta^{2}(t) \in \mathbf{I}_{\mathbf{K}}^{-} \mathbf{L}_{2}$ for all $t \in \mathbb{R}$. The space $\mathbf{I}_{\mathbf{K}}^{+} \mathbf{L}_{2}\left(\mathbf{I}_{\mathbf{K}}^{-} \mathbf{L}_{2}\right)$ is called a stable (unstable) invariant space of equation (11).

Theorem 2. (i) The solutions $\eta=\eta(t)$ to problem (11), (12) have exponential dichotomies for any $\alpha \in \mathbb{R}, \lambda \in \mathbb{R}_{-}, \eta_{0} \in \mathbf{H}_{l \mathbf{K}}^{q} \mathbf{L}_{2}$.

(ii) The phase space of problem (11), (12) coincides with a stable invariant space for any $\alpha \in \mathbb{R}_{-}$and $\lambda \in \mathbb{R}_{+}$, and the phase space of problem (11), (12) coincides with an unstable invariant space for any $\alpha, \lambda \in \mathbb{R}_{+}$.

\section{Computational Experiment}

On the two-dimensional torus $T^{2}=[0,1] \times[0,1]$, consider the map $\Phi: S \rightarrow U$, where $U \subset T^{2}$, and $S$ is the inside of the square with vertices at the points $(0,0),(0,1),(1,0)$, and $(1,1)$. Similarly to Section 1 , we construct spaces of random $\mathbf{K}$-variables $\mathbf{S}_{\mathbf{K}} \mathbf{L}_{2}$ on the map $S$, namely, in the space $L_{2}(S)$. Elements of this space are presented by the vectors $\zeta=\sum_{k=1}^{\infty} \lambda_{k} \xi_{k} \varphi_{k}$, where $\left\{\varphi_{k}\right\}$ is the basis in the space $L_{2}(S)$

If $\eta(t)$ is a solution to equation (11) in the space of random $\mathbf{K}$-variables on the twodimensional torus $\mathbf{H}_{0 \mathbf{K}}^{q} \mathbf{L}_{2}$, then $\zeta(t)=\Phi[\eta(t)]$ is a solution to equation

$$
(\lambda-\Delta) \stackrel{\circ}{\zeta}=\alpha \Delta \zeta
$$

defined in the space $\mathbf{S}_{\mathbf{K}} \mathbf{L}_{2}$. The converse statement is also true. Namely, if $\zeta(t)$ is a solution to equation (14), then $\eta(t)=\Phi^{-1}[\zeta(t)]$ is a solution to equation (11). Therefore, if solutions to equation (14) are exponentially stable (unstable) (in the sense of Definition 4), then solutions to equation (11) are exponentially stable (unstable).

Remark 1. The region on the torus corresponding to the considered map does not cover the entire gluing line, which is two intersecting circles, i.e. the "meridian" and "parallel" of the torus. The interiors of the squares $S_{1}-S_{4}$ form an atlas. Here $S_{1}$ has vertices at the points $(0.5,0),(0.5,1),(1.5,0)$, and $(1.5,1), S_{2}$ has vertices at the points $(0,0.5)$, $(1,0.5),(0,1.5)$, and $(1,1.5), S_{3}$ has vertices at the points $(0.5,0.5),(1.5,0.5),(0.5,1.5)$, and $(1.5,1.5), S_{4}$ has vertices at the points $(1,1),(1.5,1),(1,0.5)$, and $(1.5,1.5)$. In order to study the stability of solutions to equation (11), it suffices to consider only one map.

Let us construct an algorithm to study the stability of solutions to equation (14).

Step 1. Set the coefficients $\alpha \neq 0, \lambda \neq 0$, the square $S=[0,1] \times[0,1]$, the interval of change of the time parameter $t$ from 0 to $T$, the number $n_{t}$ of partitions of the given interval, and calculate the step in $t: h_{t}=\frac{T}{n_{t}}$.

Step 2. In the space $L_{2}(S)$, define basis functions by the function $\varphi=\sin (m x) \cos (n y)$.

Step 3. Construct the vector $\zeta_{0}=\sum_{k=1}^{K} \frac{1}{k^{2}} \xi_{k} \varphi_{k}$, where $\xi_{k}$ is a random variable $\sim N(0,1)$ (i.e., $\xi_{k}$ is a random variable with normal distribution, zero mathematical expectation, and dispersion equal to unity).

Step 4. Find the relative spectrum $\mu_{k}=\frac{\alpha \lambda_{k}}{\lambda-\lambda_{k}}$, where $\lambda_{k}=-k^{2}$.

Step 5. Check that the relative spectrum belongs to the phase space. If $\left(\zeta_{0}, \varphi\right)_{L_{2}} \neq 0$, then then the program displays a message that there exist no solutions and stops the work. Otherwise, go to the next step. 
Step 6. If $\lambda>0$ and $\alpha>0$, then the program displays a message that the solution is stable, constructs the solution (Example 1) based on formula (13), and stops the work. Otherwise, i.e. for $\lambda>0$ and $\alpha<0$, the program displays a message that the solution is unstable, constructs the solution (Example 2) based on formula (13), and stops the work.

Step 8. If $\lambda<0$ and there exists $k$ such that $\lambda=\lambda_{k}$, then find the number $n=k$. Otherwise, find the maximum value $k$ at which $\lambda_{k}>\lambda$, and set $n$ to be equal to this maximum value.

Step 9. If $\alpha>0$, then stable solutions are constructed in the cycle from 1 to $n-1$, and unstable solutions are constructed in the cycle from $n+1$ to $M$ (Example 3). Otherwise, unstable solutions are constructed in the cycle from 1 to $n-1$, and stable solutions are constructed in the cycle from $n+1$ to $M$ (Example 4 ).

Example 1. The solutions to problem (11), (12) are exponentially stable for $\lambda=4$, $\alpha=5$. Fig. 1 shows the graphs of the solution for $t=0,1.5$ with the step 0.5 ,

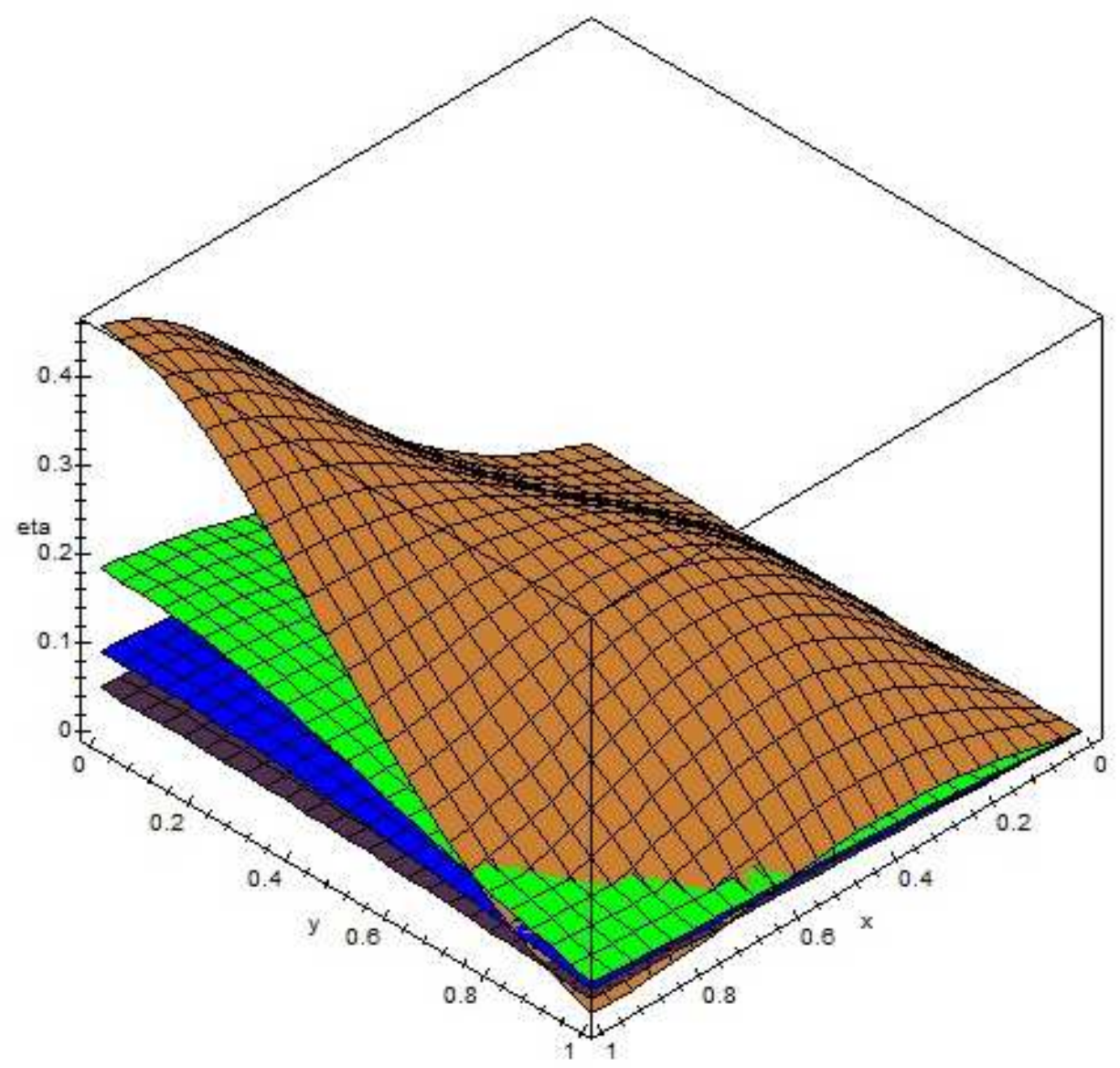

Fig. 1. Exponential stability of solutions for $\lambda=4, \alpha=5, t \in[0,1.5]$ with the step 0.5 (gold color $-t=0$, green color $-t=0.5$, blue color $-t=1$, violet color $-t=1.5$ ).

and Fig. 2 shows the graphs of the solution for $t \in[0,3]$ in the section $y=0.5$. 


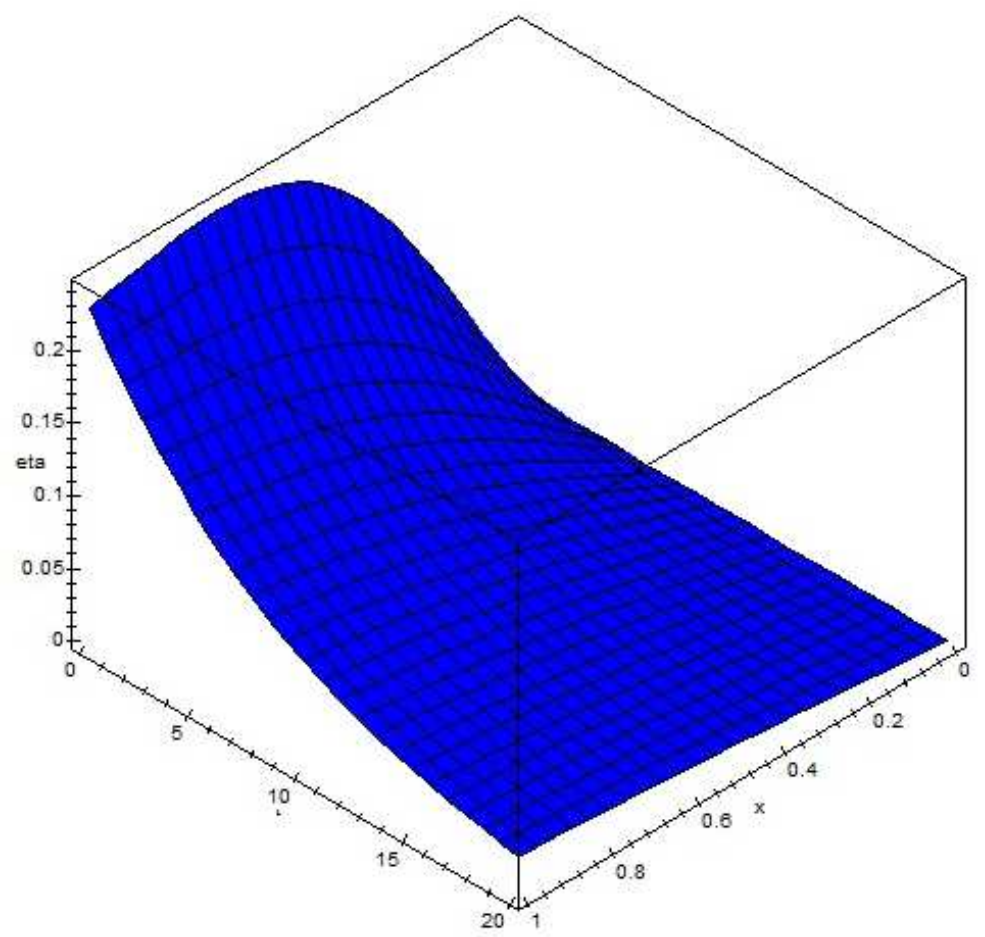

Fig. 2. Exponential stability of solutions for $\lambda=4, \alpha=5, t \in[0,3]$ in the section $y=0.5$.

Example 2. The solutions to problem (11), (12) are exponentially unstable for $\lambda=-4$, $\alpha=0.5$. Fig. 3 shows the graph of the solution for $t \in[0,3]$ in the section $y=0.5$.

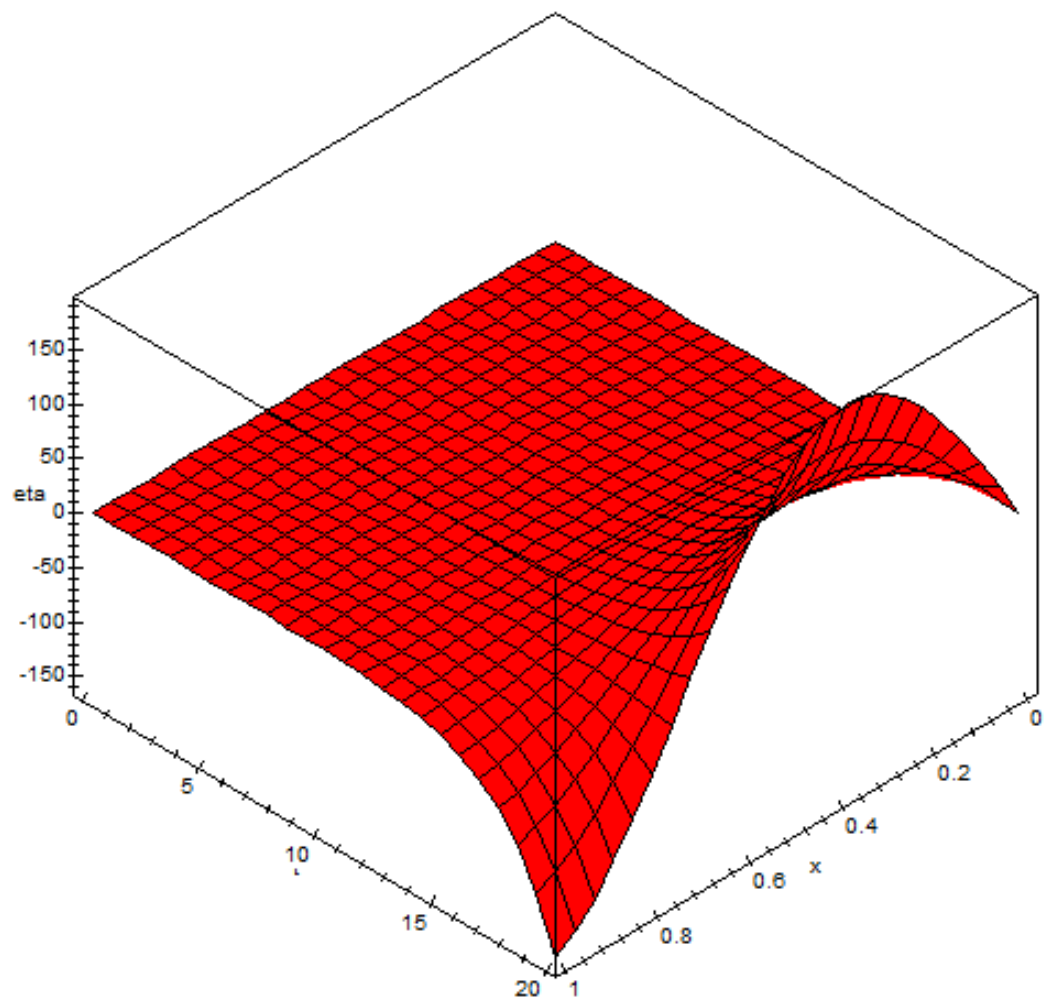

Fig. 3. Exponential unstability of solutions for $\lambda=4, \alpha=-5, t \in[0,3]$ in the section $y=0.5$. 
Example 3. The solutions to problem (11), (12) have exponential dichotomy for $\lambda=-4$, $\alpha=0.5$. The solutions

$$
\zeta_{+}(t)=\sum_{l=1}^{n-1} e^{\mu_{l} t}\left(\sum_{k=1}^{M} \lambda_{k} \xi_{k}\left(\varphi_{k}, \varphi_{l}\right)_{L_{2}} \varphi_{l}\right)
$$

belong to a stable invariant space, and the solutions

$$
\zeta_{-}(t)=\sum_{l=n+1}^{K} e^{\mu_{l} t}\left(\sum_{k=1}^{M} \lambda_{k} \xi_{k}\left(\varphi_{k}, \varphi_{l}\right)_{L_{2}} \varphi_{l}\right)
$$

belong to an unstable invariant space. Fig. 4 shows the graph of the solution for $t \in[0,7]$ in the section $y=0.5$.

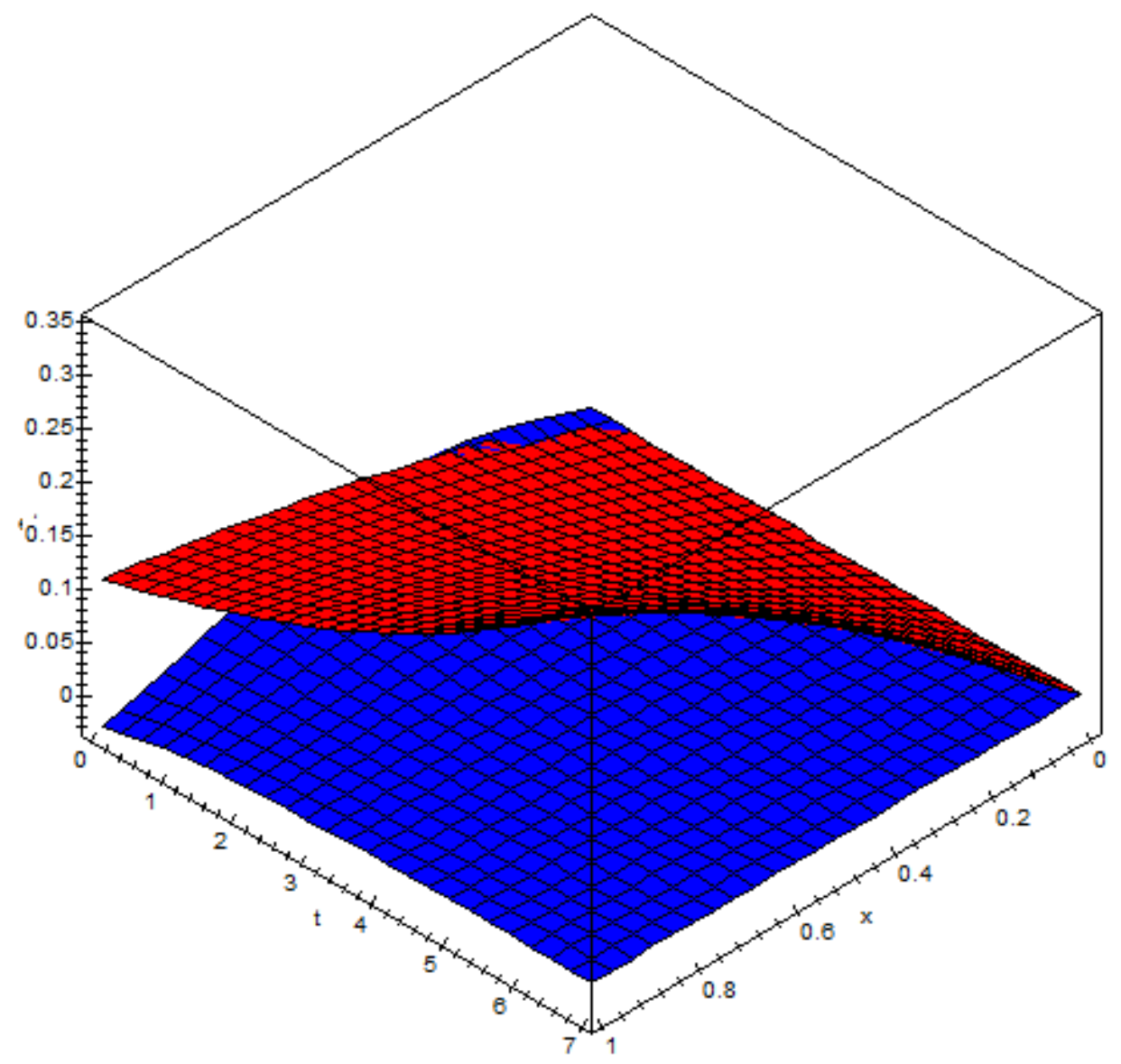

Fig. 4. Exponential dichotomies for $\lambda=-4, \alpha=0.5, t \in[0,3]$ in the section $y=0.5$.

Example 4. The solutions to problem (11), (12) have exponential dichotomy for $\lambda=-4$, $\alpha=-0.5$. The solutions

$$
\zeta_{-}(t)=\sum_{l=1}^{n-1} e^{\mu_{l} t}\left(\sum_{k=1}^{M} \lambda_{k} \xi_{k}\left(\varphi_{k}, \varphi_{l}\right)_{L_{2}} \varphi_{l}\right)
$$


belong to an unstable invariant space, and the solutions

$$
\zeta_{+}(t)=\sum_{l=n+1}^{K} e^{\mu_{l} t}\left(\sum_{k=1}^{M} \lambda_{k} \xi_{k}\left(\varphi_{k}, \varphi_{l}\right)_{L_{2}} \varphi_{l}\right)
$$

belong to a stable invariant space. Fig. 5 shows the graph of the solution for $t \in[0,7]$ in the section $y=0.5$.

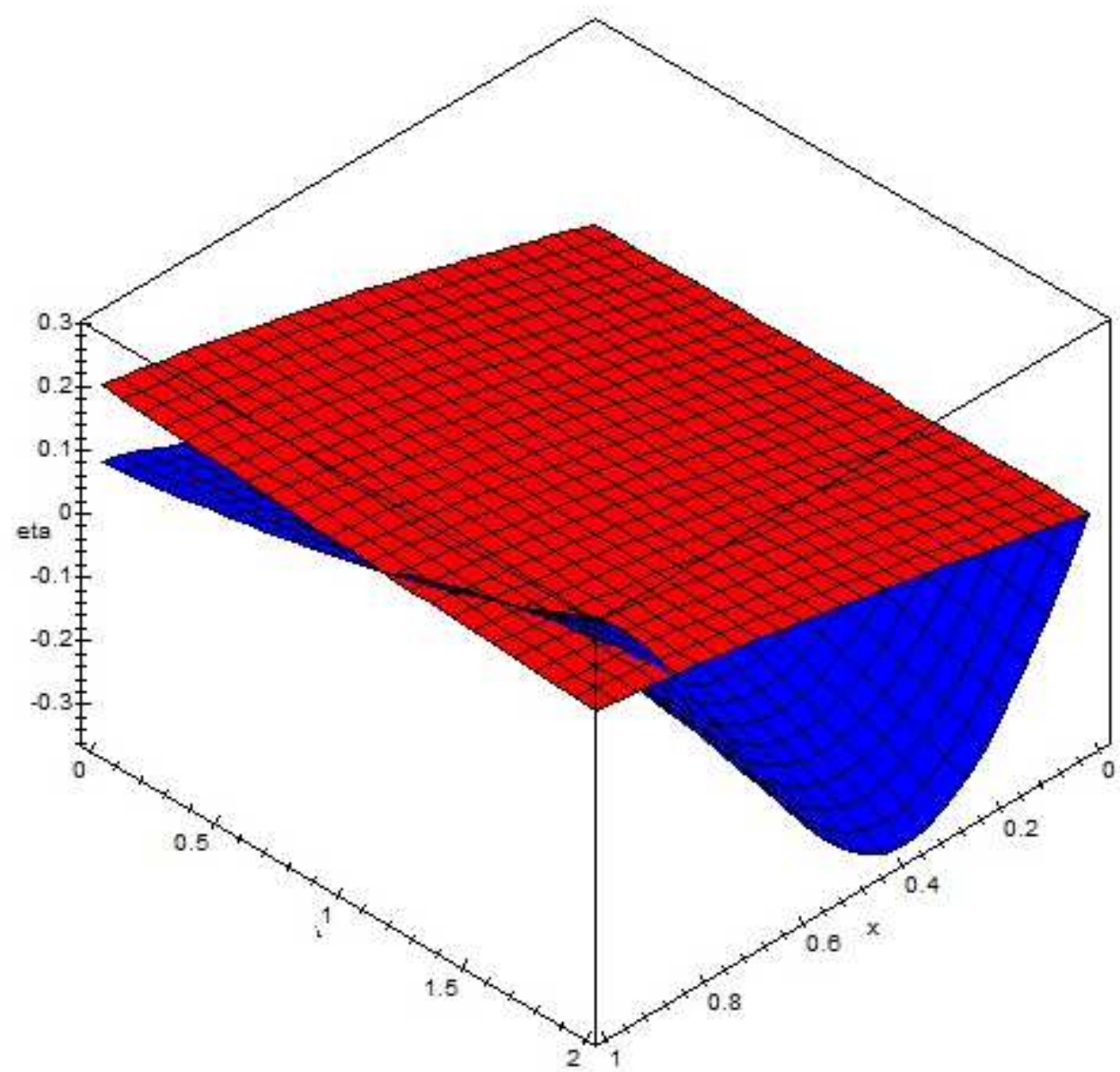

Fig. 5. Exponential dichotomies for $\lambda=-4, \alpha=-0.5, t \in[0,3]$ in the section $y=0.5$.

\section{References}

1. Sviridyuk G. A. The Cauchy Problem for a Linear Singular Operator Equation of Sobolev Type. Differ. Uravn., 1987, vol. 12, pp. 2168-2171.

2. Sviridyuk G. A., Keller A. V. Invariant spaces and dichotomies of solutions of a class of linear equations of Sobolev type. Izv. Vyssh. Uchebn. Zaved. Mat., 1997, no 5, pp. 60-68.

3. Shafranov D. E. The Splitting of the Domain of the Definition of the Elliptic Self-adjoint Pseudodifferential Operator. Journal of Computation and Engineering Mathematics, 2015, vol. 2, no. 3, pp. 60-64. DOI:10.14529/jcem150306 
4. Sviridyuk G. A., Brychev S. V. Numerical Solution of Systems of Equations of Leontief Type Izv. Vyssh. Uchebn. Zaved. Mat., 2003, no. 8, 46-52.

5. Sviridyuk G. A. Sobolev Type Equations on Graphs. [Nonclassical Equations of Mathematical Physics]. Novosibirsk, 2002, pp. 221-225. (in Russian).

6. Moskvicheva P. O. A Numerical Experiment for the Barenblatt - Zheltov Kochina Equation in a Bounded Domain. Journal of Computation and Engineering Mathematics, 2017, vol. 4, no 2, pp. 41-48. DOI: 10.14529/jcem170204

7. Gliklikh Yu. E. Global and Stochastic Analysis with Applications to Mathematical Physics. Springer, London, Dordrecht, Heidelberg, N.Y., 2011.

8. Favini A., Sviridiuk G. A., Manakova N. A. Linear Sobolev Type Equations with Relatively p-Sectorial Operators in Space of "noises". Abstract and Applied Analysis, 2015, vol. 2015, art.no. 697410. - 8 p. DOI: $10.1155 / 2015 / 697410$

9. Shestakov A. L., Sviridyuk G. A., Khudyakov Yu. V. Dynamic Measurements in Space of "Noises". Bulletin of the South Ural State University. Series: Computer Technology, Control, Radioelectronic, 2013, vol. 13, no. 2, pp. 4-11. (in Russian).

10. Keller A. V., Shestakov A. L., Sviridyuk G. A., Khudyakov Y. V. The Numerical Algorithms for the Measurement of the Deterministic and Stochastic Signals. Semigroups of Operators - Springer Proceedings in Mathematics and Statistics, 2015, vol. 113, pp. 183-195. DOI: 10.1007/978-3-319-12145-1_11

11. Zagrebina S. A., Soldatova E. A., Sviridyuk G. A. The Stochastic Oskolkov Model of the Oil Transportation by the Pipeline. Semigroups of Operators - Springer Proceedings in Mathematics and Statistics, 2015, vol. 113, pp. 183-195. DOI: 10.1007/978-3-319-12145-1_20

12. Favini A., Sviridiuk G. A., Sagadeeva M. A. Linear Sobolev Type Equations with Relatively p-Radial Operators in Space of "Noises". Mediterranean Journal of Mathematics, 2016, vol. 13, no 6, pp. 4607-4621. DOI: 10.1007/s00009-016-0765-x

13. Favini A., Sviridiuk G. A., Zamyshlyaeva A. A. One Class of Sobolev Type Equations of Higher Order with Additive "White Noise". Communications on Pure and Applied Analysis, 2016, vol. 15, no 1, pp. 185-196. DOI: 10.3934/cpaa.2016.15.185

14. Favini A., Zagrebina S. A., Sviridiuk G. A. Multipoint Initial-Final Value Problems for Dynamical Sobolev-Type Equations in the Space of Noises. Electronic Journal of Differential Equations, 2018, vol. 2018, no 128, pp. 1-10.

15. Shafranov D. E., Kitaeva O. G. The Barenblatt - Zheltov - Kochina model with the Showalter - Sidorov Condition and Additive "White Noise"in Spaces of Differential Forms on Riemannian Manifolds without Boundary. Global and Stochastic Analysis, 2018, vol. 5, no 2, pp. 145-159. DOI: 10.14529/mmp190204 
16. Kitaeva O. G., Shafranov D. E., Sviridiuk G. A. Exponential Dichotomies in the Barenblatt - Zheltov - Kochina Model in Spaces of Differential Forms with "Noise". Bulletin of the South Ural State University. Series: Mathematical Modeling, Programming and Computer Software, 2019, vol. 2, no 12, pp. 47-57. DOI: $10.14529 / \mathrm{mmp} 190204$

17. Warner F. W. Foundations of Differentiable Manifolds and Lie Groups. SpringerVerlag, N.Y., 1983.

Olga G. Kitaeva, PhD (Math), Associate Professor, Department of Mathematical and Computer Modelling, South Ural State University (Chelyabinsk, Russian Federation), kitaevaog@susu.ru.

Received August 9, 2019.

\title{
ЭКСПОНЕНЦИАЛЬНЫЕ ДИХОТОМИИ ОДНОГО НЕКЛАССИЧЕСКОГО УРАВНЕНИЯ В ПРОСТРАНСТВАХ ДИФФЕРЕНЦИАЛЬНЫХ ФОРМ НА ДВУМЕРНОМ ТОРЕ С "ШУМАМИ"
}

\section{O. Г. Китаева}

\begin{abstract}
Статья посвящена исследованию устойчивости решений линейного стохастического уравнения Баренблатта - Желтова - Кочиной в пространствах гладких дифференциальных форм, определенных на двумерном торе. Показано существование устойчивого и неустойчивого инвариантных пространств решений в пространствах "шумов" при различных параметров, характеризующих среду и свойства жидкости. Доказано существование экспоненциальных дихотомий решений, заключающихся в расщеплении фазового пространства на прямую сумму двух инвариантных пространств. Причем решения начинающиеся в одном из этих пространств экспоненциально растут, оставаясь в этом пространстве, а решения начинающиеся в другом пространстве экспоненциально убывают, также оставаясь в этом пространстве. Построен алгоритм нахождения устойчивых и неустойчивых решений стохастического уравнения Баренблатта - Желтова - Кочиной на одной из карт двумерного тора, в котором учитывается принадлежность начальных данных фазовому пространству. Алгоритм реализован в среде Maple. При различных значения параметров, входящих в уравнение Баренблатта - Желтова - Кочиной, представлены графики экспоненциально устойчивого и экспоненциально неустойчивого решений, лежащих в устойчивом и неустойчивом инвариантных пространствах. Так же представлены графики решений имеющих экспоненциальную дихотомию.
\end{abstract}

Ключевые слова: уравнения соболевского типа; стохастические уравнения; дифференциальные формы; экспоненииальные дихотомии. 


\section{Литература}

1. Свиридюк, Г. А. Задача Коши для линейного сингулярного уравнения типа соболева / Г. А. Свиридюк // Дифференциальные уравнения. - 1987. - Т. 23, № 12. C. $42168-2171$.

2. Свиридюк, Г. А. Инвариантные пространства и дихотомии решений одного класса линейных уравнений типа Соболева / Г. А. Свиридюк, А. В. Келлер // Изв. ВУЗ. Матем. - 1997. - № 5. - С. 60-68.

3. Moskvicheva, P. O. A Numerical Experiment for the Barenblatt - Zheltov - Kochina Equation in a Bounded Domain / P. O. Moskvicheva // Journal of Computation and Engineering Mathematics. - 2017. - V. 4, № 2. - P. 41-48.

4. Shafranov, D. E. The Splitting of the Domain of the Definition of the Elliptic Selfadjoint Pseudodifferential Operator / D. E. Shafranov // Journal of Computation and Engineering Mathematics. - 2015. - V. 2, № 3. - P. 60-64.

5. Свиридюк, Г. А. Численное решение систем уравнений леонтьевского типа / Г. А. Свиридюк, С. В. Брычев // Известия высших учебных заведений. Математика. -2003 .- № 8. - С. 46-52.

6. Свиридюк, Г. А. Уравнения соболевского типа на графе / Г. А. Свиридюк // Неклассические уравнения математической физики. - Новосибирск, 2002. C. $221-225$.

7. Gliklikh, Yu. E. Global and Stochastic Analysis with Applications to Mathematical Physics / Yu. E. Gliklikh. - London, Dordrecht, Heidelberg, N.Y.: Springer, 2011.

8. Favini, A. Linear Sobolev Type Equations with Relatively p-Sectorial Operators in Space of "noises" / A. Favini, G. A. Sviridyuk, N. A. Manakova // Abstract and Applied Analysis. - 2015. - V. 2015. - A/N 697410. - 8 c.

9. Шестаков, А. Л. Динамические измерения в пространствах «шумов» / А. Л. Шестаков, Г. А. Свиридюк, Ю. В. Худяков // Вестник ЮУрГУ. Серия: Компьютерные технологии, управление, радиоэлектроника. - 2013. - Т. 13, № 2. - С. 4-11.

10. Keller, A. V. The Numerical Algorithms for the Measurement of the Deterministic and Stochastic Signals / A. V. Keller, A. L. Shestakov, G. A. Sviridyuk, Y. V. Khudyakov // Semigroups of Operators - Springer Proceedings in Mathematics and Statistics. - 2015. - V. 113. - P. 183-195.

11. Zagrebina, S. A. The Stochastic Oskolkov Model of the Oil Transportation by the Pipeline / S. A. Zagrebina, E. A. Soldatova, G. A. Sviridyuk // Semigroups of Operators - Springer Proceedings in Mathematics and Statistics. - 2015. - V. 113. P. 317-325.

12. Favini, A. Multipoint Initial-Final Value Problems for Dynamical Sobolev-Type Equations in the Space of Noises / A. Favini, S. A. Zagrebina, G. A. Sviridyuk // Electronic Journal of Differential Equations. - 2018. - V. 2018, № 128. - P. 1-10. 
13. Favini, A. One Class of Sobolev Type Equations of Higher Order with Additive "White Noise" / A. Favini, G. A. Sviridyuk, A. A. Zamyshlyaeva // Communications on Pure and Applied Analysis. - 2016. - V. 15, № 1. - P. 185-196.

14. Favini, A. Multipoint Initial-Final Value Problems for Dynamical Sobolev-Type Equations in the Space of Noises / A. Favini, A. S. Zagrebina, G. A. Sviridiuk // Electronic Journal of Differential Equations. - 2018. - V. 2018, № 128. - P. 1-10.

15. Shafranov, D .E. The Barenblatt - Zheltov - Kochina Model with the Showalter Sidorov Condition and Additive "White Noise" in Spaces of Differential Forms on Riemannian Manifolds without Boundary / D. E. Shafranov, O. G. Kitaeva // Global and Stochastic Analysis. - 2018. - V. 5, № 2. - P. 145-159.

16. Kitaeva, O. G. Exponential Dichotomies in the Barenblatt - Zheltov - Kochina Model in Spaces of Differential Forms with "Noise" / O. G. Kitaeva, D. E. Shafranov, G. A. Sviridiuk // Вестник ЮУрГУ. Серия: Математическое моделирование и программирование. - 2019. - V. 2, № 12. - С. 47-57.

17. Warner, F. W. Foundations of Differentiable Manifolds and Lie Groups / F. W. Warner. - N.Y.: Springer-Verlag, 1983.

Китаева Ольга Геннадъевна, кандидат физико-математических наук, доцент, дочент кафедры уравнений математической физики, Южно-Уральский государственный университет (г. Челябинск, Российская Федерация), kitaevaog@susu.ru.

Поступила в редакиию 9 августа 2019 г. 